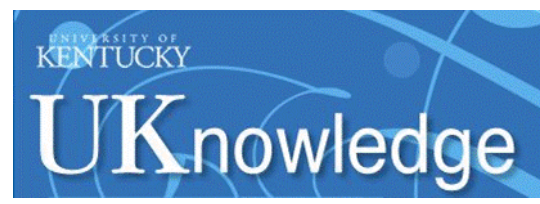

University of Kentucky

UKnowledge

$11-2015$

\title{
The Role of Self-Leadership in Service Leadership
}

Daniel T. L. Shek

University of Kentucky

Cecilia M. S. Ma

The Hong Kong Polytechnic University, China

Ting Ting Liu

Wuhan University, China

Andrew M. H. Siu

The Hong Kong Polytechnic University, China

Follow this and additional works at: https://uknowledge.uky.edu/pediatrics_facpub

Part of the Pediatrics Commons

Right click to open a feedback form in a new tab to let us know how this document benefits you.

\section{Repository Citation}

Shek, Daniel T. L.; Ma, Cecilia M. S.; Liu, Ting Ting; and Siu, Andrew M. H., "The Role of Self-Leadership in Service Leadership" (2015). Pediatrics Faculty Publications. 200.

https://uknowledge.uky.edu/pediatrics_facpub/200

This Article is brought to you for free and open access by the Pediatrics at UKnowledge. It has been accepted for inclusion in Pediatrics Faculty Publications by an authorized administrator of UKnowledge. For more information, please contact UKnowledge@lsv.uky.edu. 


\section{The Role of Self-Leadership in Service Leadership}

Digital Object Identifier (DOI)

https://doi.org/10.1515/ijdhd-2015-0455

\section{Notes/Citation Information}

Published in International Journal on Disability and Human Development, v. 14, no. 4, p. 343-350.

(C) 2015 Walter de Gruyter GmbH, Berlin/Boston

The copyright holders have granted the permission for posting the article here. 


\section{Daniel T.L. Shek*, Cecilia M.S. Ma, Ting Ting Liu and Andrew M.H. Siu The role of self-leadership in service leadership}

DOI 10.1515/ijdhd-2015-0455

Received May 25, 2014; accepted June 21, 2014; previously published online September 12, 2015

\begin{abstract}
One of the core beliefs of the service leadership curriculum proposed by the Hong Kong Institute of Service Leadership and Management is that 'Every day, every human occupies a position of leadership and possesses the potential to improve his leadership quality and effectiveness'. This core belief is in sharp contrast to some of the mainstream leadership theories that only a few people and elites can be leaders. In this paper, a lecture plan regarding the nature of self-leadership with reference to service leadership is presented. The topics include definitions and concepts of self-leadership, relationships between self-leadership and service leadership, ways to promote self-leadership, and conclusions and reflections. During the lecture, students are also encouraged to reflect on how well they lead their lives, with reference to the concepts of self-management, self-monitoring, and self-improvement.
\end{abstract}

Keywords: self-improvement; self-leadership; self-management; service leadership.

\section{Introduction}

In the daily use of the term 'leadership', people usually think that only those who possess exceptional qualities

\footnotetext{
*Corresponding author: Daniel T.L. Shek, PhD, FHKPS, BBS, SBS, JP, Chair Professor of Applied Social Sciences, Faculty of Health and Social Sciences, Department of Applied Social Sciences, The Hong Kong Polytechnic University, Room HJ407, Core H, Hunghom, Hong Kong, P.R. China, E-mail: daniel.shek@polyu.edu.hk; Centre for Innovative Programmes for Adolescents and Families, The Hong Kong Polytechnic University, Hong Kong, P.R. China; Department of Social Work, East China Normal University, Shanghai, P.R. China; Kiang Wu Nursing College of Macau, Macau, P.R. China; and Division of Adolescent Medicine, Kentucky Children's Hospital, University of Kentucky, Lexington, Kentucky, USA

Cecilia M.S. Ma: Department of Applied Social Sciences, The Hong Kong Polytechnic University, Hong Kong, PRChina Ting Ting Liu: Department of Sociology, Wuhan University, Wuhan, P.R. China

Andrew M.H. Siu: Department of Rehabilitation Sciences, The Hong Kong Polytechnic University, Hong Kong, P.R. China
}

can become leaders (i.e. not everyone can be a leader). An underlying belief of this assumption is that only few people can become leaders. However, with the emergence of the strengths perspective and positive psychology, there is a growing belief that leadership is not the special privilege of the elite. With the belief that everybody has potential, it logically follows that everybody is (and can be) a leader. In an era of service economy, leaders are not just confined to those in the top level of the hierarchy. In reality, front-line service providers have to make important leadership decisions that have an impact on other people as well. For example, a courier has to make alternative plans on how to deliver the mails to customers when his/her truck breaks down. A social worker also has to make important decisions if his/her client threatens to set fire in an interview room.

The concept of self-leadership was introduced into the field of leadership research as a challenge to the mainstream approach that primarily focused on how leaders or supervisors influenced their followers [1]. The notion of self-leadership is based on the assertions that people manage and lead themselves and that people's actions are ultimately dependent on internal motives, despite being subject to external forces [2]. In other words, the assertion of self-leadership is based on a positive view of human nature that people have potential to lead and to improve themselves.

Self-leadership propositions were initially intended to guide employees or subordinates to lead themselves in occupational performance $[1,3]$. It was pointed out that due to increasingly expanded sizes of organizations and specialized duties of managers nowadays, leaders cannot have all the answers and make all the decisions [4]. Therefore, encouraging followers to lead themselves and assume certain responsibilities is an inevitable demand of modern management. With the research development in this field, the discussion on self-leadership is thus extended to other areas of personal life and organizational behavior $[2,5]$.

In a general sense, self-leadership means 'a comprehensive self-influence perspective that concerns leading oneself toward performance of naturally motivating tasks as well as managing oneself to do work that must be done but is not naturally motivating' [6, p. 589] The process of self-leadership requires the ability to move into the awareness of and conscious control over the subconscious 
imagery, cognitions and thoughts of oneself, based on which different self-helping strategies are developed [3]. Hence, apart from followers, self-leadership can also serve as strategies for leaders or any individuals to promote their personal development.

The positive outcomes of self-leadership have been clearly documented in the existing literature. Based on a student sample, Prussia, Anderson, and Manz found that the application of different self-leadership strategies could effectively promote academic performance via enhanced self-efficacy [7]. Carmeli, Meitar, and Weisberg also revealed that employees' self-leadership was positively associated with their innovative work behaviors [8]. Another study showed that, given a working environment that allowed greater autonomy and freedom, members with higher self-leadership had higher levels of job satisfaction [9]. Moreover, research has also shown the positive effects of self-leadership on health and psychological well-being [10]. In view of the broad range of benefits selfleadership brings to individuals and organizations, it has been incorporated into different leadership theories as an important competence that an effective leader should possess, such as transformational leadership [11], shared leadership [12], authentic leadership [13], and transcendent leadership [14].

\section{Relationship between self- leadership and service leadership}

In the theory of service leadership, self-leadership is particularly essential to a service leader. According to the model proposed by the Hong Kong Institute of Service Leadership and Management (HKI-SLAM), leadership is a kind of service given to ethically satisfy the needs of self, others, groups, communities, systems, and environments. Self-serving efforts aim at ethically improving one's full range of competencies (e.g. knowledge and skills, plus character strengths), ability potential (e.g. physical, mental, and spiritual health), social networks (e.g. loyal friends and allies), material resources (e.g. wealth and prestige items), and willingness (prosocial values and attitudes) to help satisfy the needs of self and others [15]. In other words, a service leader should be a self-leader first to ensure that he/she is able to consistently provide quality service to others (i.e. leading oneself before leading others).

The important role of self-leadership in service leadership can be reflected in two aspects. First, self-leadership enables one to build the capacities that are necessary for effectively leading and serving others. In the process of self-leadership, the achievement of personal goals is addressed cognitively and behaviorally by reducing the discrepancies from standards and refining the appropriateness of the standards. These purposeful efforts will serve as the internal sources of sustainable personal development. As mentioned above, people who are good at self-leadership can demonstrate more competent psychological and behavioral performance [8, 10]. There is also research showing that self-leading processes, such as self-understanding and self-regulation, are positively related to the development of empathy and morality [16, 17]. Therefore, people can cultivate qualities that allow them to perform service leadership by committing to leading themselves toward the achievement of the objectives.

In addition, leaders' self-leading practice can generate role-model effects on followers that, in turn, encourages their development. It is emphasized in service leadership that a leader should serve the needs of followers and nurture their development. Numerous studies have shown that promoting self-leadership among group members can effectively boost individual competencies as well as group productivity $[18,19]$. One approach to cultivate self-leaders among the subordinates could be the leader's role-modeling practice. As shown in Rich's study, followers' perceptions of their managers' role-modeling behaviors are positively associated with their trust in the managers and also influenced their performance and job satisfaction [20]. Hence, it is argued that followers can learn how to achieve personal development through selfleadership by modeling the practice of a leader who has a strong sense of self-leadership. To sum up, self-leadership is an important part of effective service leadership, which is a prerequisite for consistently providing quality services to others.

In the second term of the 2012/2013 academic year, The Hong Kong Polytechnic University offered a General Education subject called 'Service Leadership' on a pilot basis, with the objective of cultivating adolescent developmental assets in university students so that students can become a competent service leader in future. The subject has 14 2-h lectures and in its 10th lecture, the concept of self-leadership is proposed. In the following, the detailed lecture content of Lecture Ten of the course 'Service Leadership', together with the rationale behind the curriculum design and the activities used, is presented in a chronological order. It is hoped that the lesson plan can serve as an exemplar of how service leadership can be implemented in a university setting. 


\section{Overview of the lecture}

Based on the thesis that leading oneself is a prerequisite for leading others, Lecture Ten introduces the concept of self-leadership, its association with service leadership, and the theoretical and practical strategies for promoting self-leadership so as to promote students' development of self leadership and service leadership. Specifically, the content is divided into four parts: (1) definitions and concepts of self-leadership, (2) relationships between selfleadership and service leadership, (3) ways to promote self-leadership, and (4) conclusions and reflections. Three class activities and a warm-up activity are scheduled in this 2-h lecture. The rundown of the lecture is shown in Table 1.

It is expected that after taking this lecture, students will be able to achieve the following learning outcomes: (1) understand the concept of self-leadership and its components, (2) appreciate the importance of self-leadership in personal achievement and group development, (3) recognize the vital role of self-leadership in effective service leadership, (4) assess and reflect on their quality as a selfleader, and (5) identify conceptual and practical strategies for promoting self-leadership.

\section{Content of the lecture}

\section{Warm-up activity: Are you good at self-management?}

The lecture starts with a warm-up activity to help students gain a preliminary understanding of self-leadership before they get into theoretical details. This activity includes a 2-min video clip and several follow-up questions. First, the video entitled 'Procrastination song' is played, in which several young people disclose their personal experiences and feelings about their procrastinating behaviors in a musical manner. Some questions are designed as a follow-up to the video to lead students to reflect on their own performance in self-management. These questions include 'Do you think you are a procrastinating person? Why?', 'Are you punctual for appointments?', 'Do you usually comply with the plans made by yourself?', 'Have you done something on a regular basis for a long time?', and 'Are you able to adjust yourself to be positive when experiencing frustration?' This activity ends by linking the concepts of self-management and self-leadership.

Table 1: Rundown of the lecture.

\begin{tabular}{|c|c|c|}
\hline Activity & Procedures & Materials \\
\hline 1. Opening (5 min) & $\begin{array}{l}\text { Opening: } \\
\text { - Recap Lecture } 9\end{array}$ & $\begin{array}{l}\text { Lecture PPT } \\
\text { Slide } 2-3\end{array}$ \\
\hline \multirow[t]{2}{*}{ 2. Warm-Up Activity (5 min) } & "Are You Good at Self-Management?" & Lecture PPT \\
\hline & Purpose: To help students gain a preliminary understanding on self-leadership. & Slide 4 \\
\hline 3. Lecture (15 min) & Part I: Definitions and Concepts of Self-Leadership & $\begin{array}{l}\text { Lecture PPT } \\
\text { Slides } 5-11\end{array}$ \\
\hline \multirow[t]{2}{*}{ 4. Class activity (15 min) } & “Are You a Good Self-Leader?” & Lecture PPT \\
\hline & Purpose: To help students assess their competence in self-leadership. & $\begin{array}{l}\text { Slides } 12-14 \\
\text { Worksheet } 1\end{array}$ \\
\hline 5. Lecture (10 min) & Part II: Relationship between Self-Leadership and Service Leadership & $\begin{array}{l}\text { Lecture PPT } \\
\text { Slides } 15-18\end{array}$ \\
\hline \multirow[t]{2}{*}{ 6. Class activity (20 min) } & “Draw Your Ideal Self-Leader” & Lecture PPT \\
\hline & $\begin{array}{l}\text { Purpose: To facilitate students' understanding about attributes crucial to being a } \\
\text { good self-leader }\end{array}$ & $\begin{array}{l}\text { Slides } 19-20 \\
\text { A3 papers } \\
\text { Color pens }\end{array}$ \\
\hline 7. Lecture $(15 \mathrm{~min})$ & Part III: Ways to Promote Self-Leadership & $\begin{array}{l}\text { Lecture PPT } \\
\text { Slides } 21-26\end{array}$ \\
\hline \multirow[t]{2}{*}{ 8. Self-reflection exercise (15 min) } & “Self-Leader: On the Way!” & Lecture PPT \\
\hline & Purpose: To help students identify ways to practice and promote self-leadership. & $\begin{array}{l}\text { Slide } 27 \\
\text { Worksheet } 2\end{array}$ \\
\hline 9. Wrap-up (5 min) & Part IV: Conclusion & $\begin{array}{l}\text { Lecture PPT } \\
\text { Slides 28-32 }\end{array}$ \\
\hline 10. Sharing $(5 \mathrm{~min})$ & $\begin{array}{l}\text { Sharing } \\
\text { - Invite two students to share their thoughts after taking this lecture }\end{array}$ & $\begin{array}{l}\text { Lecture PPT } \\
\text { Slide } 33\end{array}$ \\
\hline
\end{tabular}




\section{Part I: Definitions and concepts of self-leadership}

As mentioned above, Manz defined self-leadership as a comprehensive self-influence process leading oneself to accomplish different types of tasks [6]. There are several steps one needs to fulfill in the process. First, one should perceive the situation by comparing its current state with desirable standards and identify the gap. Then, the gap needs to be addressed by efforts to reduce the discrepancy. Third, the outcomes of the new behaviors are assessed by re-evaluating the gap between the facts and the standards. Based on the updated evaluation of the situation, another cycle of self-regulation begins [1]. In other words, selfleadership is a process of applying self-influence strategies to promote desired behaviors and reduce undesired behaviors $[1,2]$.

Manz categorized self-leadership strategies into the following: behavior-focused strategies, natural reward strategies, and constructive thought pattern strategies $[2,6]$. Specifically, behavior-focused strategies are mainly behaviors targeted toward self-assessment, self-discipline, and self-reward, such as conducting self-analysis to form an awareness of personal behaviors, establishing longterm goals, identifying specific behaviors to enhance or modify, practicing desired behaviors, and applying selfrewards or self-punishment. Natural reward strategies refer to positive perceptions and experiences associated with tasks to be accomplished, which usually involve a belief in, commitment to, or enjoyment of the work for its own value. These strategies can be applied by seeking tasks that are enjoyable, or by modifying perceptions about the tasks to increase self-control, motivation, and fulfillment. Constructive thought pattern strategies aim to build and adjust thought patterns regarding the work to be done in favorable ways. Particular methods include evaluating and improving beliefs and assumptions, mental imagery of positive performance, positive self-talk, and use of effective scripts that serve as individual counterparts to organizational rules, policies, and procedures.

It is argued that self-leadership differs from other related concepts (e.g. self-management, self-control) by more fully incorporating intrinsic motivation, and applying a wider range of self-influence strategies to address higher level standards that govern self-influence [1]. Three underlying questions can be used to understand selfleadership: 'What is to be done?', 'How is it to be done?', and 'Why is it to be done?' Put another way, self-leadership is accompanied by a cognitive process, in which the goals/outcomes, methods/approaches, and also reasons/ values of actions are identified. It is the cognitive process that distinguishes self-leadership from other types of selfmanagement that primarily rely on external factors (e.g. command, reward, incentives) [21].

Self-leadership is thought to be a construct that falls along a continuum ranging from the lower end representing externally managed behavior to the higher end indicative of self-leadership behavior. In the middle of the continuum lies self-management. For people who are externally managed, their behavior is solely determined by extrinsic incentives, with little consciousness to 'what to do', 'how to do', and 'why [a task] should be done'. One can move further up to self-management when approaches to accomplishing certain tasks (i.e. 'how') are well identified and the motivation for actions is mainly dependent on extrinsic incentives. A behavior can be regarded as self-leadership only when 'what', 'how' and 'why' are all addressed, and both internal and external incentives are incorporated.

As a routine practice, the definition of key concepts is introduced at the start of the lecture. In this part, Manz's definition of self-leadership is explained with examples of 'naturally motivating tasks' and 'work that must be done but is not naturally motivating'. Then the teacher introduces three categories of self-leadership strategies and how they can be applied in different kinds of tasks based on specific living cases. The cognitive process that addresses 'what', 'how', and 'why' is emphasized by comparing self-leadership with external management and self-management that are more extrinsically motivated.

After showing the continuum of self-leadership, a story is shared with students to facilitate their understanding of the above-mentioned distinctions. It mainly talks about three masons who are doing the same work but have different views on the task. While the first mason focuses on the superficial fact that he is chipping away at a block of stone, the second believes he is just following what his boss asks him to do, and the third one perceives his work as instrumental in building a beautiful church. Students are then led to discuss which one of them would become a self-leader based on the learning in this part.

\section{Class activity 1: Are you a good self-leader?}

The first major activity is scheduled at the end of Part 1, which is a questionnaire that helps students become more aware of their competencies of self-leadership. The questionnaire is based on the Revised Self-leadership Questionnaire, which has 35 items in nine distinct subscales representing primary self-leadership strategies, such as self-reward, self-goal setting, self-punishment, 
self-observation, self-cueing, natural reward strategies, rehearsal (visualizing successful performance), self-talk, and evaluating beliefs and assumptions [22]. This scale has been demonstrated to be a reliable and valid instrument to measure self-leadership skills, behaviors, and cognitions [22].

In this activity, students are first requested to complete the questionnaire in a self-administered manner, and are then instructed to calculate their total and subscale scores. To help students engage in reflective learning, the teacher requests them to identify their strengths and weaknesses as well as aspects they hope to improve most. Sharing of the test results and personal reflections in class is highly encouraged. This activity is wrapped up by emphasizing that self-leadership is a comprehensive perspective that involves a variety of specific strategies.

\section{Part II: Relationship between self-leadership and service leadership}

Previous studies have shown that self-leadership is associated with a wide range of positive outcomes at individual and team levels. As service leadership is defined as a kind of service that satisfies the needs of others by consistently providing quality personal services to oneself, others and systems, the benefits of self-leadership can roughly be mapped onto the three realms of service leadership. At the individual level, self-leading people could demonstrate more self-efficacy, perceive higher levels of job satisfaction, and perform more enthusiastically and competently in work, which could lead people to achieve career success $[7,9,10,23]$. With regard team outcomes, promoting selfleadership among team members (including leaders and followers) could reduce the personal control of the leader over the group, build trust and cohesion within group, nurture the autonomy of followers, thus facilitating group effectiveness and achievement $[1,6,21]$. Similarly, such systems as hierarchical organizations or communities, which are composed of highly self-leading members and units, operate more effectively than those lacking necessary capacities for rational self-government [6, 24, 25]. To conclude, positive consequences of self-leadership in different levels can, to some extent, serve the needs of self, others, and systems for development, and are thus associated with service leadership in its three realms.

To introduce the concepts in this part of the lecture, students are asked several questions to provoke their thoughts about the relationship between self-leadership and service leadership with the adoption of a multilevel perspective. Examples of the questions include the following: 'Have you practiced self-leadership? What benefits do you think self-leadership can bring about to an individual?', 'Do you expect your group members to be capable of leading themselves? Why?', 'In your opinion, what distinguishes systems composed of self-leading members from those poor in self-management?' Aside from thought-provoking questions and discussion, several mottos and quotes are used to facilitate students' understanding of the importance of self-leadership in service leadership.

\section{Class activity 2: Draw your ideal self-leader}

The second class activity follows the second part of the lecture, and takes the form of picture drawing. This activity is designed to facilitate students' understanding about attributes crucial to a good self-leader. As argued in the theoretical part, an effective service leader must be a selfleader first - one who possesses a range of self-leadership competences, such as self-observation, self-control, and self-empowerment. The present activity encourages students to link human bodily organs to these abilities in symbolic terms and highlight the abilities they regard as important through drawing. Students are expected to add different organs to a figure of man on the paper, and provide explanations of what self-leadership ability the organ represents and why it is important.

To conduct this activity, the teacher first makes a demonstration to the students. For example, a pair of big eyes can be drawn in the figure, as a person with sharp eyes can perform better self-observation, which is the starting point of self-leadership. Then the teacher distributes to each group an A3 paper and color pens, and asks them to draw a human figure that can represent an ideal selfleader according to their conception. After the artwork is completed, each group of students is invited to show their drawing and explain it to the class. This activity is wrapped up by summarizing the key traits of a good selfleader and introducing the topic of the next part.

\section{Part III: Ways to promote self-leadership}

One key message conveyed to the students is that selfleadership can be developed and promoted [6]. It is a process of developing one's own self through discovering who he/she is, what he/she wants to be, and what he/ she cares about. As previously mentioned, there are three categories of strategies that can be applied for self-leadership: behavior-focused, natural reward, and constructive 
thought pattern strategies [2, 7]. These strategies include a variety of particular approaches, such as self-observation, self-management of cues, self-goal setting, self-reward/ criticism and rehearsal, which are effective in leading oneself to attain his/her personal goals [1].

In the practical sense, one can follow the process that includes the steps of self-assessment, goal setting, self-monitoring, and consistent practice to develop self-leadership. Specifically, self-assessment enables a person to form an awareness of when and why certain personal behaviors occur, and thus identify which behavior is desirable and which one should be eliminated or changed. Based on the awareness, the individual can set specific personal goals to achieve desirable performance. A commonly used approach in goal setting is the 'SMART' principle, which suggests a goal that is 'specific', 'measurable', 'achievable', 'realistic' and 'time-bound', and can strengthen the motivation for action and increase the odds of goal attainment [26]. With the goals well established, one needs to focus on accomplishing the tasks ahead, thus moving to a self-monitoring or self-regulation stage. A series of specific strategies mentioned above can be used at this stage to evaluate and advance the progress toward the accomplishment of goals, such as positive self-talk, positive imagery before the actual behavior, elimination or modification of dysfunctional beliefs, and self-reward for desired performance or self-punishment for undesired performance [22]. It is noteworthy that selfleadership does not end with the temporary achievement of certain behavior, but demands long-term adherence instead. Therefore, consistent practice is necessary for one to build a habitual behavioral pattern through the self-leadership process.

Students are led to go through each of the stages of performing self-leadership as well as particular strategies that can be adopted in each stage. Different approaches, including reflective questions, case analysis and teacher's self-disclosure, are used throughout this part to assist the teaching. For example, to show students the way of self-assessment, the teacher asks them to reflect on themselves based on the results of questionnaire testing conducted in the activity session and identify which aspects they want to improve most. Questions like 'How do you evaluate other areas of your life, such as academic performance, family relationship, and spiritual well-being?' and 'How do your family or your trusted friends perceive you?' are also posed to engage students in a more thorough selfassessment. As for goal setting, two sets of descriptions of personal goal are compared and analyzed to facilitate students' understanding of the SMART principle and its application.

\section{Class activity 3: Self-leader: On the way!}

As a variety of approaches and strategies are introduced in Part III of the lecture, the third activity is expected to help students identify various ways to apply self-leadership in a practical manner. Considering the fact that the examination period is approaching, strategies that can be used to direct students' self-leadership in preparing for the examination are discussed. Students are requested to specify the task to be accomplished, which can be group project, individual term paper, or other important works. Based on the tasks identified, they need to make a self-assessment of their performance so far, then set 'SMART' goals for themselves, and devise a plan showing how they would do to monitor the progress toward the goal attainment. A worksheet (Appendix 1) is designed for this activity.

In this activity, the teacher's main task is to instruct students to finish the worksheet first. Then, several students are invited to share their plans to the rest of the class. The teacher then wraps up the activity by encouraging students to stick to their plans, highlighting the fact that effective service leadership starts with self-leadership.

\section{Part IV: Conclusion and reflections}

The major task in the conclusion part is to review and summarize the knowledge points of this lecture. Under the instructions of the teacher, students recall what they have learnt, including the definition and features of selfleadership, positive outcomes associated with service leadership, and self-leading strategies. The teacher then highlights some of the key points identified earlier for emphasis. This part is wrapped up with the routine procedures of post-lecture evaluation and student sharing.

\section{Discussion}

In the lecture described above, self-leadership is linked with service leadership in a university setting. There are several issues that can be highlighted for curriculum refinement. First, students can be further encouraged to reflect on their lifestyles with respect to the question of self-discipline and self-management. For example, students can be encouraged to put their reflections into writing and develop a plan for self-improvement. Second, the relationship between self-leadership and Confucian virtues introduced in the earlier part of the subject can be explored. Moreover, it would be interesting to explore 
how psychosocial competencies, such as behavioral competence and self-efficacy, can contribute to self-leadership [27-30]. Third, students can be invited to reflect on the notions of self-leadership and elitist leadership, and the extent to which they support which view. Finally, the teacher can invite students to consider the question of 'standards' with reference to values and principles that can be used to determine one's performance.

\section{Appendix 1}

\section{THE HONG KONG POLYTECHNIC UNIVERSITY DEPARTMENT OF APPLIED SOCIAL SCIENCES APSS2820 Service Leadership}

Lecture Ten: Self-leadership \& Service Leadership

\section{Self-Leader: On the Way!}

The assessment of this course is coming! How would you prepare for your group project or term paper? Please make an action plan for the successful accomplishment of the tasks in a "selfleadership" way. You can pick one task (group project or term paper) as the goal of your plan. If you think some other thing is more important to you in the coming weeks, you can also make your plan based on that work.

Let's see whether you can fulfill your plan as expected!

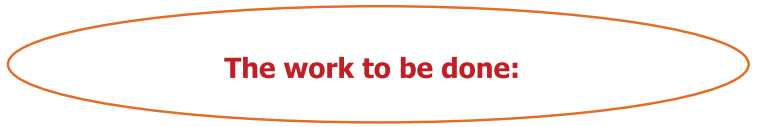

Self-Assessment: How is your performance so far?

Goal setting: What is the specific goal you hope to achieve?

S.

M.

A.

R.

T.

Self-Regulation: What would you do to monitor your progress? 


\section{References}

1. Stewart GL, Courtright SH, Manz CC. Self-leadership: a multilevel review. J Manage 2011;37:185-22.

2. Manz CC, Neck C. Mastering self-leadership: empowering yourself for personal excellence. New Jersey: Prentice Hall, 1998.

3. Markham SE, Markham IS. Self-management and selfleadership reexamined: a levels-of-analysis perspective. Leadersh Q 1995;6:343-59.

4. Lovelace KJ, Manz CC, Alves JC. Work stress and leadership development: the role of self-leadership, shared leadership, physical fitness and flow in managing demands and increasing job control. Hum Resour Manage R 2007;17:374-87.

5. Campion MA, Medsker GJ, Higgs AC. Relations between work group characteristics and effectiveness: implications for designing effective work groups. Pers Psychol 1993;46:823-47.

6. Manz CC. Self-leadership: toward an expanded theory of self-influence processes in organizations. Acad Manage Rev 1986;11:585-600.

7. Prussia GE, Anderson JS, Manz CC. Self-leadership and performance outcomes: the mediating influence of self-efficacy. J Organ Behav 1998;19:523-38.

8. Carmeli A, Meitar R, Weisberg J. Self-leadership skills and innovative behavior at work. Int J Manpow 2006;27:75-90.

9. Roberts HE, Foti RJ. Evaluating the interaction between selfleadership and work structure in predicting job satisfaction. J Bus Psychol 1998;12:257-67.

10. Dolbier CL, Soderstrom M, Steinhardt MA. The relationships between self-leadership and enhanced psychological, health, and work outcomes. J Psychol 2001;135:469-85.

11. Mavrinac MA. Transformational leadership: peer mentoring as a values-based learning process. Portal-Libr Acad 2005;5:391-404.

12. Houghton JD, Neck CP, Manz CC. Self-leadership and superleadership. In: Pearce CL, Conger JA, editors. Shared leadership: reframing the hows and whys of leadership. Thousand Oaks, CA: Sage, 2003:123-40.

13. Klenke K. Authentic leadership: a self, leader, and spiritual identity perspective. Int J Leadersh Stud 2007;3:68-97.

14. Crossan M, Vera D, Nanjad L. Transcendent leadership: strategic leadership in dynamic environments. Leadersh Q 2008;19: 569-81.

15. Chung PY. Hong Kong Institute of Service Leadership and Management (SLAM) curriculum framework. Unpublished manuscript, 2011.
16. Eisenberg N. Emotion, regulation, and moral development. Annu Rev Psychol 2000;51:665-97.

17. Damon W, Hart D. Self-understanding and its role in social and moral development. In: Bornstein MH, Lamb ME, editors. Developmental psychology: an advanced textbook. Hillsdale, N): Erlbaum, 1992:421-64.

18. Neck CP, Manz CC. Thought self-leadership: the impact of mental strategies training on employee cognition, behavior, and affect. J Organ Behav 1996;17:445-67.

19. Stewart GL, Manz CC. Leadership for self-managing work teams: a typology and integrative model. Hum Relat 1995;48: 747-70.

20. Rich GA. The sales manager as a role model: effects on trust, job satisfaction, and performance of salespeople. J Acad Marketing Sci 1997;25:319-28.

21. Manz CC. Leading employees to be self-managing and beyond: toward the establishment of self-leadership in organizations. J Manage Syst 1991;3:15-24.

22. Houghton JD, Neck CP. The revised self-leadership questionnaire: testing a hierarchical factor structure for self-leadership. J Managerial Psychol 2002;17:672-91.

23. Raabe B, Frese M, Beehr TA. Action regulation theory and career self-management. J Vocat Behav 2007;70:297-311.

24. Manz CC, Sims HP. Searching for the "unleader": organizational member views on leading self-managed groups. Hum Relat 1984;37:409-24.

25. Herbert-Cheshire L. Contemporary strategies for rural community development in Australia: a governmentality perspective. J Rural Stud 2000;16:203-15.

26. Bovend'Eerdt TJ, Botell RE, Wade DT. Writing SMART rehabilitation goals and achieving goal attainment scaling: a practical guide. Clin Rehabil 2009;23:352-61.

27. Catalano RF, Berglund ML, Ryan JA, Lonczak HS, Hawkins JD. Positive youth development in the United States: research findings on evaluations of positive youth development programs. Ann Am Acad Pol Soc Sci 2004;591: 98-124.

28. Damon W. What is positive youth development? Ann Am Acad Pol Soc Sci 2004;591:13-24.

29. Shek DT, Sun RC. The Project P.A.T.H.S. in Hong Kong: development, training, implementation, and evaluation. J Pediatr Adolesc Gynecol 2013;26:S2-9.

30. Shek DT, Sun RC, editors. Development and evaluation of positive adolescent training through holistic social programs (P.A.T.H.S.). Berlin: Springer, 2013. 